\title{
ESTIMATION OF THE ENERGY SECURITY LEVEL AND DEFINITION OF THE CRITERIA FOR DAMAGE FORECASTS
}

\author{
F.I. Molochko, A.F. Molochko \\ Byelorussian heat energy institute \\ Romanovskaja Sloboda 5, 220048 Minsk, Republic of Belarus \\ e-mail: mvt@beltei.by \\ J. Ekmanis, N. Zeltins, V. Zebergs \\ Institute of Physical Energetics, \\ 21. Aizkraukles Str., Riga, LV 1006 LATVIA \\ e-meil: zeltinsh@edi.lv
}

\begin{abstract}
In the work, the energy security indicators in a region (a state) are considered, and two general directions are proposed for search among the criteria for estimation and forecast of the damage inflicted by power supply limitations: based on the differentiated calculations for each economic subject, and on the generalised indices of regional economy. Of especial interest is analysis of a recently introduced damage intensity factor and its dependence on the level of limitations and the type of energy carriers.
\end{abstract}

Key words: energy security, security indicators, estimation criteria, damage.

\section{INTRODUCTION}

Estimation of the energy security level for a separate region (a state) can be performed using indicators that characterize quantitatively the existing security threat and its degree based on:

- comparison of the current and expected values of indicators with some predefined threshold (limiting) levels;

- determination of the qualitative state of energy security that could be characterized as normal $(\mathrm{N})$ and critical (C).

The list of indicators that can be used for this purpose and the threshold levels determined based on the expert estimates are presented in Table 1.

Most of the tabulated indicators are used in the international practice. As mentioned above, the threshold values of indicators are set based on the expert estimates. Such an approach is not always justified when substantiated decisions must be made on the realisation of definite directions that would ensure improvement of the energy security level. It should be taken into account that concrete technological measures in all possible directions require solid investments; therefore, the usefulness of their implementation should be based on the relevant cost estimation regarding these measures and possible damage in the case of negative consequences resulting from their realisation. When selecting among the measures related to the category of energy security it should be borne in mind that this 
category differs from the reliability of energy supply. The problems of reliable energy supply in most cases are solved within the limits of a branch/an industry in the stage of contemplating the energy supply systems for concrete objects and populated areas by planning organisations, whereas the energy security issues concern separate regions or industrial zones, and should be solved first of all by politicians and complex-directive bodies, with involving afterwards the relevant branches/industries and planning organisations.

Table 1

Energy security indicators in a region and estimation of their level

\begin{tabular}{|c|c|c|c|}
\hline \multirow{2}{*}{ Nr. } & \multirow{2}{*}{ Indicators } & \multicolumn{2}{|c|}{ Threshold levels } \\
\hline & & $\mathrm{N}$ & $\mathrm{C}$ \\
\hline 1. & $\begin{array}{l}\text { Energy intensity of the gross domestic product (GDP), } \mathrm{kg} / \$ \\
\text { (GDP assigned to purchasing power priority) }\end{array}$ & 0.35 & 0.5 \\
\hline 2. & $\begin{array}{l}\text { Share of domestic energy resources in the boiler-furnace fuel (BFF) } \\
\text { balance in a region, } \%\end{array}$ & 30 & 15 \\
\hline 3. & $\begin{array}{l}\text { Share of possible domestic production in the total electric energy } \\
\text { consumption, \% }\end{array}$ & 100 & 85 \\
\hline 4. & $\begin{array}{l}\text { Share of motor fuel consumption ensured by the oil production in a } \\
\text { region, \% }\end{array}$ & 35 & 15 \\
\hline 5. & $\begin{array}{l}\text { Share of the dominating energy resource (gas) in the region in its } \\
\text { heat- and electro-energy industry, \% }\end{array}$ & 65 & 90 \\
\hline 6. & $\begin{array}{l}\text { Share of the dominating energy resource (gas) in the region in its } \\
\text { boiler-furnace fuel (BFF) consumption, } \%\end{array}$ & 50 & 90 \\
\hline 7. & Share of the dominant supplier of energy resources, $\%$ & 65 & 85 \\
\hline 8. & $\begin{array}{l}\text { Share of the thermal plants capable of working on two and more } \\
\text { mutually replaceable fuel types, } \%\end{array}$ & 80 & 50 \\
\hline 9. & $\begin{array}{l}\text { Depletion of fixed industrial funds (FIF)/assets of the fuel-energy } \\
\text { complex (FEC) enterprises, \% }\end{array}$ & 45 & 75 \\
\hline 10. & Provision with BFF reserve (in natural gas and heavy fuel oil), days & 90 & 30 \\
\hline 11. & $\begin{array}{l}\text { Ratio of the total installed capacity of generating plants to the } \\
\text { maximum actual load in a power system (reservation), } \%\end{array}$ & 120 & 95 \\
\hline 12. & $\begin{array}{l}\text { Ratio of the investments in FEC enterprises to the value of their } \\
\text { FIF/assets, \% }\end{array}$ & 6.0 & 4.0 \\
\hline
\end{tabular}

\section{CHOICE OF CRITERIA AND EVALUATION OF DAMAGE}

\subsection{General definitions}

\subsubsection{Categories of events}

The category of energy security should include the events resulting in power supply limitations caused by:

- political measures;

- economic blockade;

- military operations;

- natural calamities;

- diversions; 
- major emergency events;

- limited technical resource;

- financial conflicts; and so on.

\subsubsection{Differentiation of limitations} these are:

The limitations can be differentiated by value and duration; in particular,

- interruptions in supplying all kinds of the energy carriers from one state for indefinite time or for a pre-defined period (the term is agreed beforehand);

- interruption in supplying the main by volume (majority) energy carrier from one state for indefinite time or for the term agreed beforehand;

- interruption in supplying the minority (by volume) energy carriers from one state;

- partial limitations in supplying all kinds of the energy carriers or one majority carrier from one state;

- complete disruption of power supply caused by a failure of the system as a whole;

- disruption of the heat energy supply to an industrial centre caused by a largescale failure in heating systems;

- deficit of one kind of fuel-energy resources (FER) caused by limited technical opportunities due to the ill-timed putting of generating or transporting capacities into operation.

The extent of damage from the listed above and other possible events depends not only on the value and duration of limitations but also on the period of the year in which these events took place.

\subsubsection{Differentiation of the consequences}

In general terms, the consequences of limitations could be differentiated by the following stages:

The first - when minor limitations cause damage that is felt only in energy supplying organisations owing to undersupply of their products, while the consumers of FER do not suffer serious damage; however, in this situation the comfort of people's life deteriorates (lack of hot water, low indoor temperature, worse working conditions in some public and industrial buildings, and so on), which indirectly leads to damage also for the FER consumers owing to lower labour productivity.

The second - when, in addition to the first stage, individual groups of industrial enterprises or all of them do not work, except for those securing the necessities of life for people. Here the case in point is the damage inflicted by product undersupply, which concerns both the energy supplying organisations and the FER consumers for which the limitations are introduced.

The third - in addition to those of second stage, limitations are introduced also into the social sphere in the form of periodic cutting-off of power, hot and cold water, television, and (partially) traffic; pre-school and all other institutions of the education system do not work, etc. In this case, apart from the damage due to undersupply of products by all the branches of industry and agriculture, damage arises also in other areas of activity (consumer services, tourist business, civil 
engineering, etc.); this damage to the society is mainly composed of moral and intellectual constituents, which are impossible to evaluate in terms of money.

The fourth - when, as a result of long-lasting lack of energy carriers in winter time, apart from the damage caused by underproduction of commodities also damage on the basic funds/assets of industrial and social spheres is inflicted (the heat and water supply systems are let freeze, the equipment that cannot withstand low temperatures fails to operate, the necessity arises to evacuate people from dwelling houses, and so on).

\subsection{Plausible criteria of damage estimation}

In practice, as a rule, the value of actual damage from any negative events is expressed in terms of money concretely for the objects located in the area where these events take place, with the main constituents being the damage from undersupply of products (non-rendered services) and the damage from destruction of the basic and circulating funds. In this case, the cost of undersupplied products and the value of destructed basic and circulating funds are used as appropriate criteria.

In the formulation of the considered energy security problem it is necessary to determine not the actual but possible (predictable) damage in the case when one of the above listed (or, possibly, of some other) events occurs. Correspondingly, also other methodical approaches are required - both for the choice of a criterion itself and for determination of its value.

Obviously, different authors could offer various scenarios; however, in the given work two general directions are proposed to make a search for criteria:

first - the estimation of forecasted damage based on the differentiated calculations for each economic subject and for its separate constituents;

second - the estimation based on the generalised indices of a region's economy on the whole, with differentiation by branches (sub-branches), and, possibly, by major producers.

To solve the set task using the first direction it is necessary to gather a great body of current initial information and to process it, while the forecasting will also need statistic information for a long enough time span. However, even if the requested information is available and the used methodical approaches are correct, the damage value obtained for one subject will not reflect in full measure the damage for a regional economy, since it should be taken into account that among economic subjects mutual relations exist - the activities of one such subject affect the results of many others, so the damage in the succeeding stages could be close to or even higher than that in the first one.

In this regard the use of the first direction is justified when the calculations are to be performed for one object or for a small number of objects, and if in the succeeding stages (for other objects) there is little likelihood of damage.

The second direction is preferable, since it allows a complex estimate to be made, with due consideration for the chain of regional interconnections, and requires less initial information to be collected and processed.

The extent of damage depends not only on the severity and duration of limitations but also on the constituents that will be included into this category. 
In particular, the damage caused by underproduction can be calculated based on:

- the cost of a product determined by its price;

- the prime cost;

- the added value.

As a result, the total value may differ several times.

To substantiate the choice of constituents that should be included into the category of damage, we will consider their economic essence.

It is known that the commodity price, apart from the prime cost, also includes other components (extra charge, some taxes, etc.); in turn, the prime cost apart from the producer's own expenditures of labour - includes the materialised labour of other producers in the form of purchased articles, materials, stuff, energy carriers, and so on, which in the case of underproduction will not be spent at the time of FER limitations and could be used in the ensuing periods - when the limitations are taken off. Consequently, it would be illogical to include these components into the damage category. On the other hand, if the products were supplied and realised at appropriate prices, then - apart from the money that is returned to producers as the sum of prime cost and profit - some money goes into the state budget as an income component. Therefore, at underproduction the damage is inflicted not only on the producers but also on the trading organisations.

From the said above the dependence for determination of the damage value $\left(U_{n}\right)$ caused by non-supply of product at the producer's level could be formulated as

$$
U_{s}=\sum_{i=1}^{n} \Delta \Pi_{i} \cdot\left[S_{i} \cdot\left(1+r_{i}\right)-E_{n i}\right]
$$

where $\Delta \Pi_{i}$ is the value of non-supplied product of the $i$-th kind;

$S_{i} \quad$ is the prime cost per unit of the $i$-th kind product;

$r_{i} \quad$ is the planned profitability of the $i$-th kind product;

$E_{n i}$ is the component of pecuniary expenditures in the prime cost of the $i$-th kind product (purchased energy, stuff, materials, completing items, etc.).

In turn, the damage value at the level of state $\left(U_{s}\right)$ will be:

$$
U_{s}=\sum_{i=1}^{n} \Delta P_{i} \cdot\left(P_{i}-E_{n i}\right)=\sum_{i=1}^{n} \Delta P_{i} \cdot d_{i},
$$

where $P_{i}$ is the price of the $i$-th kind product;

$d_{i}$ is the added value in the price of the $i$-th kind product;

$n$ is the number of the kinds of non-supplied products.

To compare the indices for different products, enterprises, branches, and time spans with similar indices of other states as well as to minimise the influence of inflation processes it is necessary to determine the damage value also in hard currency.

Despite the simplicity of the expressions given above, for the majority of economic subjects it is difficult to determine $\Delta \Pi_{i}$ in dependence on the extent of 
possible FER limitations: on the one hand, the range of products and services can change both in volume and in structure, whereas on the other $-\Delta \Pi_{i}$ can vary depending on the kind of energy carrier on which the limitation is imposed and on the extent and duration of this limitation.

For individual economic subjects the relationship between the value of limitations on the $j$-th energy carrier and the value of non-supplied $i$-th kind of product can be expressed through the specific energy intensity of the added value as

$$
\Delta P_{j}=\frac{N_{j} \cdot \tau_{j} \cdot \gamma_{j} \cdot \alpha_{j i}}{q_{j i}}
$$

where $N_{j}$ is the claimed (agreed) consumer's capacity with respect to the $j$-th energy carrier;

$\gamma_{j}$ is the limitation value with respect to the $j$-th energy carrier;

$\tau_{j}$ is the duration of limitations on the $j$-th energy carrier;

$\alpha_{j i}$ is the damage intensity factor with respect to the $j$-th energy carrier for the $i$-th kind product;

$q_{j i}$ is the energy intensity with respect to the $j$-th energy carrier for the $i$-th kind product.

For the economic subjects the limitations can be put at once on one energy carrier and on several carriers. In this case the undersupply of products is determined with respect to the main energy carrier - i.e. a carrier whose limitations cause, first of all, the necessity to reduce the volumes of production or to stop it, independently of the limitations on other carriers. In turn, if limitations on each FER kind or on several its kinds lead to the necessity to reduce production, the undersupply value is determined on the whole, by summing up the undersupplies for each kind.

In the case of FER limitations for the whole region the influence of carrier kind is smoothed, and the value of non-supplied products $\left(\Delta \Pi_{r}\right)$ can be found from a similar expression but with the use of specific energy intensity - by their sum for all energy carriers, i.e.:

$$
\Delta \Pi_{r}=\frac{N_{\Sigma} \cdot \gamma \cdot \tau \cdot \alpha_{i r}}{q_{\Sigma}}
$$

where $N_{\Sigma}$ is the total daily regional demand for all kinds of energy carriers;

$\gamma$ is the value of limitations with respect to the total demand for FER in a region;

$\tau$ is the duration of limitations (days);

$\alpha_{i r}$ is the damage intensity factor for a region;

$q_{\Sigma}$ is the specific energy intensity of the added value (gross domestic product of the region) for the sum of all energy carriers.

Product $N_{\Sigma} \cdot \tau$ is, in fact, the absolute value of the planned consumption of energy carriers $(E)$ for a definite time period $(\tau)$, whereas the value reciprocal to the energy capacity $\frac{1}{q_{\Sigma}}=\Pi_{s p}$ reflects the GDP per energy carrier unit (energy 
intensity). Having substituted the assumed designations into Eq. (4), we obtain the expression for determination of damage as the GDP reduction in a region depending on the value of limitations, i.e.

$$
\Delta \Pi_{r}=E \cdot \Pi_{s p} \cdot \alpha_{i r} .
$$

In turn, the regional $\Pi_{s p}$ consists of the components for separate branches, i.e.

$$
\Pi_{s p}=\sum_{i=1}^{m} \Pi_{s p i} \cdot \beta_{i}
$$

where $\Pi_{s p i}$ is the specific GDP of the $i$-th branch per energy carrier unit;

$\beta_{i}$ is the share of the $i$-th branch in the total FER consumption in a region;

$m$ is the number of branches.

When the economy branches are functioning under real conditions, the consumption of energy carriers is made up from the variable component depending on the GDP volume and the relatively constant independent component (mainly consumption in the municipal services sector).

In the case when limitations on energy carriers are introduced, they first of all concern the industrial consumption, that is, its variable component, so it is logical that the sequence of limitations should be established by the criterion of the least damage from a GDP reduction.

We should take into account that the energy intensity of GDP in a region is determined by the ratio of all FER kinds (for the municipal services sector included) to the total GDP, whereas its energy intensity by branches - only by the ratio of the total FER consumption by branches, less the municipal component, to the GDP for a branch; therefore it is necessary either to exclude this component from the calculations or to determine its share for each branch.

In calculations that follow the share of the municipal component $\beta_{m u n}$ will be proportionally distributed among other branches, though only in the structural part of consumption without changing the energy intensity.

In the final form, the dependence for determination of the specific damage from GDP reduction in a region per 1 toe of limitations taking into account the branch components will be written as

$$
\Delta \Pi_{r}=E \cdot \gamma \cdot \alpha_{i r} \cdot \sum_{i=1}^{m} \Pi_{s p i} \cdot \frac{\beta_{i}}{\beta_{\text {mun }}} .
$$

The same dependence can be used to determine the damage by branches if its components are available for all economic subjects of a branch, as well as to calculate the damage for separate energy carriers.

It should be noted that, as far as regional limitations are concerned, they most often relate to one energy carrier - that is, the natural gas. However, for particular consumers such a limitation could also be expressed in the form of limitations on electric and heat energy as well as on the direct use of fuel for technological purposes. 
Into the above expressions a relatively new notion is introduced - the damage intensity factor $\left(\alpha_{i n t}\right)$. This factor is to be taken into account since at imposing limitations the direct dependence between the values of limitation and undersupply (i.e. damage) is absent up to some point.

It is evident that the dependences for different types of energy carriers will also be differing, i.e. even at the limitations being identical for each carrier its influence on the undersupply value will not be the same.

\subsection{Estimation of the damage intensity}

To find the dependence of the damage intensity factor on the limitation levels and FER types a great body of initial information should be available on the actual indices of the mentioned quantities, which as a rule are absent - both at the level of an individual economic subject and at the branch or regional scale, since none of these indices appear in statistic accounts.

In this situation it is possible to perform only an expert estimation for the regional level, and then in approximate calculations to use the values obtained (in the absence of more precise ones) for individual economic subjects.

For expert estimates the existing practice of introducing limitations could be employed. A power system uses up to ten levels of limitations on electric energy, and up to three - on heat energy. These levels depend on the consumer's category, specifics of its technological processes, possible damage at the introduction of limitations, and so on. The limitations on fuel most of all concern natural gas for a region on the whole, and afterwards these general limitations are dispersed among individual consumers.

The accumulated experience allows a statement to be made - that, even though for the majority of consumers at the total FER limitations of up to $20 \%$ the main production processes would not come to a halt, however the sanitary-hygienic conditions of the work become worse, the auxiliary processes stop; all this finally results in underproduction, with the damage intensity factor changing from 0.1 in the initial stage up to 0.9 at the finish. Further, at the limitations from $20 \%$ to $60 \%$, step-by-step outage of separate main production bays occurs, whereas the output of basic products falls proportionally to the extent of FER limitations; this means that the damage intensity factor can vary from 0.9 to 1.2 . With the limitation level rising in the range from $60 \%$ to $80 \%$ (the technical minimum) the output of basic products will be stopped by the vast majority of economic subjects, so for many of them - apart from the direct damage due to the undersupply of products for realisation - there will be a damage component in the form of penalty sanctions for non-fulfilment of their obligations to the customers - both within the regional boundaries and beyond them. The damage intensity factor exceeds unity, therefore, as existing practice evidences, the estimated level of penalty sanctions could be $1.2-1.5$.

At the limitations up to $90 \%$ (the emergency reservation) the non-stop technological processes and some life-supporting industries come to a forced halt, which results in still faster growth of damage. The expenditures on the restoration of such processes exceed many times those to be spent under normal conditions. However, if we take into account that their share in GDP is $\sim 10 \%$, the value of damage intensity factor could be estimated to be in the range 1.5-1.7. Further FER 
limitations (over 90\%) in the winter time, apart from the damage caused by underproduction, can lead to partial destruction of basic funds (heat- and water-supply systems, separate machines, mechanisms, devices, etc.), whereas the damage intensity factor rises multiply.

As mentioned above, at FER limitations up to $20 \%$ the output of basic commodities by the majority of producers does not stop, while the energy supplying organisations suffer damage owing to their underproduction; in other branches the labour productivity of workers falls down.

The damage of energy supplying organisations per unit of the undersupplied product will be determined by the tariff minus the variable component of expenditures, which is equivalent to the value added to the tariff.

The total damage for an energy- (a heat-) supplying organisation will be determined as

$$
U_{E}=\Delta E \cdot\left(T-S_{\mathrm{var}}\right)
$$

where $\Delta E$ is the value of not supplied energy (electricity, heat, fuel);

$T$ is the tariff on energy (the fuel price);

$S_{\text {var }}$ is the variable component of expenditures in the tariff on energy (in the fuel price).

\section{DAMAGE CAUSED BY PROCRASTINATIONS}

The issues of energy security in a region should be considered not only in the context of possible limitations on fuel-energy resources when there is a technical opportunity to use them but also in the cases when such an opportunity is provided at improper time - i.e. in the case of ill-timed putting into operation of the capacities for production and transfer of energy carriers. The damage for a region arising in such a situation can be caused, on the one hand, by GDP reduction (owing to the lack of fuel-energy resources), or, on the other, by receiving FER from abroad at higher prices. As distinguished from damage under usual limitations on FER, the damage caused by the absence of technical resource for production and transfer of energy carriers is incommensurably greater, since its duration is determined not by that of limitations but by the duration of putting basic funds of fuel energy complex branches into use, which could be lingering for long - not several days or months but many years. From the said it follows that, when solving the problems of how to use investments efficiently in order to supply the region with energy carriers, we should determine the efficiency taking into account the necessary level of energy security - that is, being aware of a possible long-lasting damage from tardy bringing of basic funds of FEC branches into use.

\section{CONCLUSION}

The conclusion that could be drawn from the above analysis is as follows.

At estimation of the level of energy security in a region a great number of factors should be taken into account - natural, political, economic, technical, etc., which can result in power supply limitations. In so doing, it is necessary to substantiate the damage forecast for individual economic subjects and for regional economy on the whole, with differentiation by branches, and, possibly, by major producers. 


\title{
REFERENCES
}

1. Ney, R., Ekmanis, J., Michna, J., Zeltins, N., \& Zebergs, V. (2008). Reputation risk management in the context of energy policy in CEE countries. Latv. J. Phys. Tech. Sci. (5), 48-59.

2. Neym, R., Michnam, J., Ekmanis, J., Zeltins, N., \& Zebergs, V. (2008). Energy use and related risk management problems in the context of energy policy in CEE countries. Latv. J. Phys. Tech. Sci. (1), 48-51.

3. Frormann, D., Michna, J., Stania, A., Ekmanis, J., Zebergs, V., \& Zeltins, N. (2006). Present-day problems of energy conservation policy in Central and East-European countries. Latv. J. Phys. Tech. Sci. (5), 68-74

4. Frormann, D., Michna, J., Stania, A., Ekmanis, J., Zebergs, V., \& Zeltins, N. (2006). Present risk management problems of energy and environmental policy in Central and Eastern Europe countries. Latv. J. Phys. Tech. Sci. (3), 66-73.

\section{ENERĢĒTISKĀ DROŠUMA NOVĒRTĒJUMS UN KRITĒRIJU NOTEIKŠANA ZAUDĒJUMU PROGNOZĒĚSANAI}

\author{
F.I. Moločko, A.F. Moločko, J. Ekmanis, N. Zeltiņš, V. Zēbergs \\ Kopsavilkums
}

Darbā nosaukti energeētiskā drošuma indikatori, pamatota kritēriju izvēle un uz to pamata piedāvāta metodika iespējamo energonesēju piegāžu zaudējumu novērtēšanai reǵionam pie dažādiem ierobežojumu līmeņiem.

30.01.2009. 